\title{
Virtuous reality: moral theory and research into cyber-bullying
}

\author{
Tom Harrison ${ }^{1}$
}

Published online: 12 January 2016

(c) The Author(s) 2016. This article is published with open access at Springerlink.com

\begin{abstract}
This article draws on a study investigating how 11-14 year olds growing up in England understand cyberbullying as a moral concern. Three prominent moral theories: deontology, utilitarianism and virtue ethics, informed the development of a semi-structured interview schedule which enabled young people, in their own words, to describe their experiences of online and offline bullying. Sixty 11-14 year olds from six schools across England were involved with the research. Themes emerging from the interviews included anonymity; the absence of rules, monitoring and guidance and, the challenges associated with determining the consequences of online actions. The findings demonstrate the advantages of adopting a character-based moral theory to compliment rules and/or consequence based moral theories as the basis for future research into cyber-bullying. The findings evoke some wider implications for future research into cyber-bullying that might equally be applied to investigations into other Internet related moral concerns.
\end{abstract}

Keywords Virtue ethics · Cyber-bullying · Character . Moral concern

\section{Introduction}

Research into the impact of the Internet on children and young peoples' morality has struggled to keep up with technology's rapid development and innovation. The

Tom Harrison

t.j.harrison@bham.ac.uk

1 Jubilee Centre for Character and Virtues, School of Education, University of Birmingham, Birmingham B15 2TT, UK existing body of research on how the Internet influences young people does not paint a clear picture and is often polemical (Harrison 2014; Livingston 2009). Interpretations oscillate between extremes; young people online are depicted as either predominantly truthful or dishonest, compassionate or callous, selfless or selfish, altruistic or egotistical, courageous or cowardly, or as modest or vain. What is clear is that the Internet appears to influence young people in a number of complex ways, and that it is not obvious if such influence is predominantly positive or negative. The only common ground in the literature is a broad agreement that the Internet is, in some way, having an effect on the morality of children and young people (Harrison 2014).

What is missing from many empirical studies attempting to determine what this effect might be is a philosophical foundation on which to ground the research. Recent articles have explored the Internet from deontological, utilitarian and virtue ethical lines of normative enquiry (see, for example Plaisance 2013; Vallor 2010; Lievens 2011), although the arguments expressed in them have not been put to an empirical test. The research reported in this article describes an attempt to do exactly that. It draws on an empirical study that prioritised young peoples' perspectives of cyber-bullying, with the aim of suggesting what the best moral philosophical framework for researching the pervasive issue might be. The findings of this study raise some wider implications for future research into cyberbullying, which might equally be applied to investigations into other moral concerns found on the Internet.

\section{Cyber-bullying as a moral concern}

Despite varying definitions of bullying and more specifically cyber-bullying (Tokunaga 2010), it is understood by 
many to be deliberate and hostile behaviour that is intended to harm others and as such, a moral concern (Belsey 2005; Menesini et al. 2011). The concern is great due to the high rates of cyber-bullying (Hasebrink et al. 2009) and also because of the emotional, psychological and at times, physical damage it causes its victims (Layard and Dunn 2009). Despite this, moral development and cyber-bullying research have largely been undertaken independently. Although studies have shown that the processes and reasons behind cyber-bullying do not differ much from faceto-face bullying (Froese-Germain 2008; Lenhart 2007), there is also a specific body of research that draws on moral disengagement theory (Bandura 2002) to explain why young people might bully others on the Internet. Empirical research supports a claim that the Internet acts as a 'moral disengagement mechanism' so that young people feel they are doing less moral wrong if they bully online than if they bully face-to-face (Gini 2006; Perren and GutzwillerHelfenfinger 2012; Menesini et al. 2013). Studies have also shown that cyber-bullies have less shame and guilt than offline bullies (Menesini and Camodeca 2008) and a corresponding lack of moral compassion (Pozzoli and Gini 2010).

Despite such promising research, none of these studies have sought to ground their findings in any established moral theory. This state of affairs persists despite accounts drawn from wider research into the Internet, demonstrating why such an approach might be beneficial. Several recent articles consider the rights and duties of Internet users, adopting largely deontological lines of enquiry (see, for example, Lievens 2011; Granitz and Loewy 2007; Zhang 2010; Lyu 2012). The preponderance of deontological approaches is not surprising, given that Kantianism (in some form of another) has been the moral theory of choice, until recently at least, in many areas of applied ethics (Arthur et al. 2015). Articles that explore pleasure, happiness or subjective wellbeing as a consequence of web-based interactions, adopting consequentialist lines of enquiry, are also common in the literature (see, for example, Valkenburg et al. 2006; Ali 2013; Cross et al. 2012). There has been growing awareness of virtue ethics as a serious moral rival to deontological and utilitarian theories ever since the publication of Elizabeth Anscombe's influential article Modern Moral Philosophy (1958) and Alasdair MacIntyre's book After Virtue (1981). Examples of recent articles that apply a virtue ethics theory to the Internet include: Elder (2014) who presents an Aristotelian defence of friendships online and argues that the concept of a shared life can equally be applied to online and offline friendships; and McFall (2012) who also adopts an Aristotelian conception of friendship to argue that online friendships are 'character friendships'.
In short, virtue ethics is a character based moral theory that offers an alternative framework for research into the Internet to the more directly action-guiding theories of deontology and utilitarianism. Vallor (2010) believes that several distinctive features of virtue ethics make it uniquely applicable to the domain of Internet ethics-and, furthermore, that a virtue-based perspective is needed to balance a strong utilitarian bias in the literature. Couldry (2010) agrees and argues that virtue ethics offers a more compelling and useful basis from which to study the Internet, than deontology. In particular, since rules are hard to establish and uphold online, and consequences are hard to predict, an approach to morality that is based on individual own character virtues has immediate appeal. As Plaisance (2013: 92) argues, 'rather than getting mired in the philosophical thicket regarding the motives and duties of actors in an online world we should focus on what behaviour and guidelines contribute to the flourishing of digital lives'. In this view, a virtue ethical approach offers a promising way to explore the specific moral issues found online. It is also useful to those interested in developing practical solutions for dealing with such moral issues, as it provides general guidance regarding appropriate virtue- or character-based behaviour, without reducing it to a set of codifiable rules that tend to be insensitive to particularities and contexts.

All the same, recognising Williams (1985) call for a non-reductionist approach to moral philosophy, there are merits in considering how each of the classical moral theories might be applied to a specific problem such as cyber-bullying. In doing so, the basis for pluralistic models that integrate notions of duty, consequence and virtue into future moral enquiries might well be sought. The research reported on here attempts to consider the potential interplay between different moral theories by attending to young peoples' own perspectives on cyber bullying. It holds that by taking into account the actual views of young people on the realities of their daily experience we might come to a more informed position that may be useful for further studies into the issue. Still, this study has a particular interest in exploring the potential of virtue ethics to better understand the influence of the Internet on young people, regarding it as providing an attractive and fruitful lens though which to question why people do good and/or bad things online.

\section{Research methodology}

The research reported on here is part of a larger project that investigated the influence of the Internet on the character and virtues of 11-14 year olds. This study is reported on in more general terms elsewhere (Harrison 2014) whereas this paper focuses on one section of the qualitative findings of that piece in greater detail and depth. 
The study described here sought to learn from 11 to 14 year olds, growing up in England and how they conceived the motivations of cyber-bullies. It was deemed important to hear the actual voice of the young people at both the data collection and data analysis stages. Semistructured group interviews are widely used with young people for this purpose. Unlike individual interviews, group interviews reduce adult influence in data collection methods (Heary and Hennessy 2002) by providing children of like age with the opportunity to share perceptions and experiences with peers. Horner (2000: 510) suggests that children 'are more relaxed and willing to share perceptions when discussions are held with a group of peers'. When conducting group interviews with young people, it is important to try to avoid 'answer dialogue' (Heath et al. 2009) in which young people try to answer questions in the 'expected' way, for fear of negative consequences if they get things wrong. The aim was therefore to encourage participants to speak freely and honestly about their cyberbullying experiences.

Twelve group interviews were undertaken in six schools between September and November 2013. In total, sixty 11 to 14 year olds were interviewed, of whom thirty-five were female and twenty-five male. The group interviews lasted between 30 and $45 \mathrm{~min}$. On average, there were six students in each group (smallest number was 4, largest 7), since a group of this size is considered small enough to be manageable, whilst large enough to enable a genuine group dynamic (Krueger 1994). Group interviews followed the ethical procedures outlined by the British Research Association (2011). All participants were informed about the nature of the research and were asked to give consent to participation. Parents also gave consent for their children to be involved. The interviews were recorded and transcribed.

The interview schedule mostly consisted of open questions divided into four sections. Section one addressed the question of how young people experience and/or understand cyber-bullying in their everyday lives; section two explored the difference between face-to-face and online bullying; section three sought a better understanding of the motivation of cyber-bullies; and, section four contained questions aimed at determining effective educational strategies for reducing cyber-bullying. The group interview schedule was pre-piloted and piloted to ensure that it was fit for purpose.

The data collected during interviews was analysed thematically using a deductive approach of qualitative interpretation, since the themes informing the data had already been shaped by the prior literature review. Qualitative interviews permit access to unanticipated types of data, insofar as their purpose is to allow participants to recount their own narratives and to identify the themes that best reflect their own experiences of cyber-bullying. Thematic analysis is also a way of ensuring that the key issues are highlighted and addressed (Boyatzis 1998).

\section{Contextual details: the participants and schools}

The participants were selected through cluster sampling, a method widely used by educational researchers working with schools (Robson 2011). The aim of cluster sampling is to identify a mixture of schools representing as far as possible the wider school population. The present research sites were selected on the basis that they contained a diverse range of participants within the 11-14 age bracket, in terms of gender, ethnicity, religion and rural and urban settings. Table 1 below provides details of the six schools involved.

The contact teachers in each school were asked to select a representative sample of young people to take part in the interviews. However, such selection may have been limited by availability of students at the time of the interviews, their willingness to participate, and also whether permission to participate had been granted by parents. Thus, it should be conceded that it is unlikely that representative samples were achieved in all interview groups. In addition, since participants were selected by the schools themselves, it is possible that more articulate students, and/or those of higher academic aptitude were selected to 'represent' their school. Insofar, the participants in this research might not be considered a probability sample. Still, though the selected groups cannot be said to be representative of all 11-14 year olds living in England, they may still provide useful indications of the attitudes of young people of this age group using the Internet. The results therefore need to be treated with caution, especially when attempting to draw more general conclusions from them.

The findings from the research are detailed in the section below. The quotations used in this article have been extracted from the group interviews and are generally representative of emerging themes. Genders of participants are indicated by an $\mathrm{f}$ (female) or $\mathrm{m}$ (male).

\section{Findings}

\section{Deontological challenges}

A deontological ethic regards moral conduct as the observance of rules or principles usually defined in terms of duties and/or obligations. In the group interviews questions were asked about how 'rules' and 'duties' on the Internet informs conduct, with particular regard to cyber-bullying. Two themes emerged from the data. The first was a perceived absence of clear rules online, leading to an increased sense of freedom. The second was that Internet 
Table 1 Group interview research sites

\begin{tabular}{|c|c|c|c|c|c|c|c|}
\hline School & $\begin{array}{l}\text { No. of } \\
\text { pupils on } \\
\text { roll }\end{array}$ & Age & $\begin{array}{l}\text { Type } \\
\mathrm{M} / \mathrm{F}\end{array}$ & Setting & $\begin{array}{l}\% \text { free } \\
\text { school } \\
\text { meals }\end{array}$ & Ethnicity of pupils & $\begin{array}{l}5 \text { or more } A^{*}-C \text { Grades at } \\
\text { GCSE (in Maths and English) } \\
\text { (2013) }\end{array}$ \\
\hline School A & 1074 & $11-18$ & Mixed & Urban & 17.5 & $\begin{array}{l}94 \% \text { White-British heritage } \\
\text { Remainder: minority ethnic groups }\end{array}$ & $64 \%$ \\
\hline School B & 1195 & $4-19$ & Mixed & Urban & 29.2 & $\begin{array}{l}\text { Proportion of ethnic minority groups is } \\
\text { higher than national average. }\end{array}$ & $46 \%$ \\
\hline School C & 1607 & $11-18$ & Mixed & Urban & 10 & $\begin{array}{l}\text { Majority White-British heritage; remainder } \\
\text { being from ethnic backgrounds, mostly } \\
\text { Polish }\end{array}$ & $78 \%$ \\
\hline School D & 482 & $9-13$ & Mixed & Urban & 21.5 & Most pupils White-British heritage. & $\mathrm{n} / \mathrm{a}$ \\
\hline School E & 179 & $11-19$ & Mixed & Urban & 12.3 & Not Known & $\mathrm{n} / \mathrm{a}$ \\
\hline School F & 1922 & $11-18$ & Mixed & Urban & 26 & $\begin{array}{l}\text { Proportion from minority ethnic } \\
\text { backgrounds: quarter of the national figure }\end{array}$ & $71 \%$ \\
\hline
\end{tabular}

users may easily conceal their identities, enabling them to bypass their ordinary duties.

\section{Perceived absence of rules leading to an increased sense of freedom online}

I don't know anyone who follows rules on the Internet, I don't even know where they are (m).

Many of the participants identified an increased sense of freedom from restrictions as one of the biggest differences between their online and offline lives. In schools it was said that students know what is expected of them, and furthermore that rules were enforced. A distinction was drawn between schools, which is 'full of rules' ( $\mathrm{m}$ ) and the Internet, which is a 'free for all' (m). One participant stated 'There are rules at school about no bullying, no fighting. The teachers sort this out. They don't online' (f). Participants noted that although websites used by young people might or should have more rules and regulations they do not enforce these 'as young people won't use their sites' (m). As one student put it: 'young people want freedom online' (f). Moreover, while many participants did acknowledge there are terms and conditions when they sign up to a website, they said that they did not read them and also that no one respects rules not issued by a person. This position was summed up by the observations that: 'rules in real life are more intimidating because you know that they have authority, whereas on Facebook there is no person enforcing them' (f); In addition, the scale of the Internet led many participants to doubt whether rules could ever be enforced. For example, one participant questioned how Facebook could monitor its 1 billion users.

The lack of any 'central power' or 'hierarchy' controlling the Internet has encouraged the belief that there are no rules in cyberspace and it seems to be such sense of freedom that makes the Internet so attractive to many young people. Research has shown, moreover, that such increased sense of freedom (and by association, lack of rules) also makes cyber-bullying and similar abuses more likely. For example, a study by Mishnan et al. (2009) found that cyber-bullying mostly takes place when young people are alone and unsupervised. This is pertinent given that studies show that the majority of the young people use the Internet alone (Harrison 2014) although evidence suggests that the majority of parents do monitor their child's online use (Ofcom 2014). Furthermore, young people who use their computers privately and unsupervised are more likely to be bullied (Anirban and Anoshua 2011). Shariff and Hoff (2007) have also found that schools have a difficult time supervising online activities and knowing when to involve law enforcement, or when to distinguish freedom of expression from harassment.

\section{Internet users may easily conceal their identities}

Some people use the Internet to reinvent themselves to be like a completely new person. But it can actually lead to cyber-bullying, what they say behind screens might be different to what they say to your face. $(\mathrm{m})$

A difference between online and offline forms of bullying, raised more consistently, and forcefully by participants, was that the Internet encouraged or at least allowed for anonymity. This meant that young people were able to bypass any rules and duties expected of them by operating online as someone else. It was observed that some of the websites commonly used, such as ASK FM, actually had 'anonymous' buttons on them, where it was possible to hide profile and name.

Participants held there to be a difference between open bullying in (say) a playground and being anonymously bullied through the Internet. One participant described the 
Internet as a 'mask' (m) insofar as 'you never know who you are talking to'. Another described it as a 'costume' (f) that bullies put on to avoid being detected. One participant stated: 'I think cyber-bullies are like cowards, they are hiding in their shells which is the Internet' (m). As such, cyber-bullying was often described as being 'darker' (m) and more 'underground' ( $\mathrm{m}$ ) then playground bullying.

The issue of anonymity was raised regularly in the interviews and is also discussed at length in the literature. It is considered to be one of the biggest challenges by those concerned with finding solutions to cyber-bullying (Ackers 2012; Mishnan et al. 2009). The possibility for anonymous action whilst in cyber-space also presents a challenge to deontological lines of moral thinking as it makes both rule setting as well as tracking the observance of rules difficult. Research participants thought that acting anonymously made people more likely to do things they would not normally do offline, as in face-to-face bullying there is often a more obvious power differential usually where the stronger bully torments the weaker victim, whereas in cyber-bullying the power also lies in anonymity (see also Brydolf 2007; Winter and Leneway 2008).

Perhaps even more significant is that anonymity online diminishes accountability. Accountability to others constrains conduct and without it the more anti-social aspects of human nature may come to the fore. Mishnan et al. (2009) describe the situation as bullies hiding behind the keyboard with little fear of exposure or repercussions. Weisband and Keisler (1996) found that when Internet use reduces fear of censure. Anonymity also reduces sensitivity towards their victims (Ang and Goh 2010).

Suler (2004: 322) described this mindset as 'dis-associative anonymity'. This is where the bully does not 'own their behaviour' and distances themselves from their actions. Many interviewees cited example of people they knew who acted differently online deciding to adopt a different Internet lifestyle and identity. If young people believe they cannot be found out, and that what they do online cannot be traced to other social dimensions of their lives, they are more likely to act in socially dislocated ways.

\section{Utilitarian challenges}

they think it's [cyber-bullying] a victimless crime, nothing is going to happen to anyone, they don't see people getting hurt, so why not (m).

Utilitarianism holds that the right course of action is that which maximises human wellbeing and/or reduces suffering. In this regard, evidence from interviews was clear: that participants thought that cyber-bullying was wrong and caused widespread unhappiness. However, there was also evidence that while utilitarianism provides some guide to right and wrong moral actions, features of the Internet make enforcing this principle challenging. It was commonly held that: 'seeing the consequences is a good learning tool for getting better' (f). However, it was also commonly held that due to the nature of the technology, it is hard to determine the consequences of actions online, with some consequent erosion of empathy (as empathy requires emotional identification with particular others; see Hoffman 2000).

The Internet was described by the participants variously, but words such as 'impersonal' (m) and 'faceless' (f) were used regularly. For many, the main concern was a lack of 'visual clues' ( $\mathrm{m}$ and $\mathrm{f}$ ), which meant communication could often 'go wrong' ( $\mathrm{m}$ and $\mathrm{f}$ ). This suggests that there is much scope for misinterpretation of intended meaning in communication and that it is often hard to determine the consequences of their online communications. They felt that that this meant some people might cyber-bully inadvertently. As one participant put it: 'in real life you can see it and will say sorry about things. Many don't realise their mistakes and that they are hurting you' (f). The concern appeared to be for a diminished empathy insofar as for some: being unkind 'does not mean as much online' (m); or because it is 'hard to feel as bad about online actions as those you see first-hand' (m). One participant stated that: 'because you can't see others you don't think about their pain' (f).

The absence of visual clues, so that 'people are communicating behind screens' (f) meant that many of the common ways that people make sense and bring meaning to words appeared to get lost. There was concern that: 'you can't see people's reactions, so you might not be able to tell when you are offending them'(f). Some students felt that the impersonal black and white text may also make some messages seem more threatening than intended.

The literature on cyber-bullying has also shown that victims are sometimes unintended (Shariff 2008) insofar as people are more likely to cyber-bully when they do not think they are causing harm to the victim (Willard 2002; Cross et al. 2009). Wider research has shown that cyberbullies often do not see the painful implications of their actions insofar as they are often removed from them (Campbell 2005). If the direct consequences of any particular online action are not seen, it is less likely that guilt will be felt when someone is hurt. The time/space distance of online messages may leave young people morally disengaged as the Internet enables young people to avoid feelings of guilt (Arsenio et al. 2009; Malti et al. 2010). Menesini et al. (2013) believe that the Internet encourages individuals to participate in 'egocentric reasoning', insofar as they are more concerned with gaining credibility from their peers than the outcomes of their actions. Research has 
shown that participants bullied others online because it made them feel amusing, popular, or powerful, although many indicated feeling guilty afterwards (Mishnan et al. 2010).

Utilitarianism supposes that we can weigh up moral dilemmas by calculating the consequence of our actions. However, the Internet by its very nature makes it harder for young people to determine the consequences of their actions. Both the interview data and research described in the literature show that while consequences are sometimes unintentional, they are also hard to determine. Such considerations raise doubts about the usefulness of utilitarianism for addressing problems of cyber-bullying or other web-based abuse.

\section{Virtue ethics}

When you're little you learn right and wrong. The Internet should not change the way you have been thinking and been brought up. It is still down to you what you do (f)

Virtue ethics is a moral theory that emphasises the place of character and virtues as the determining factor in why people feel and do the morally 'right thing'. The role of character in moral life was also a topic central to the group discussions of interviewees. It was generally agreed by participants that bullying in either online or offline forms seems to be due to an absence of certain virtues on the part of the bully. Virtues mentioned by the participants included care, self-discipline, compassion, humility and trust. Many interviewees held that while it might be 'easier' to bully online, a large factor determining why someone might choose to send nasty messages or not is the quality of their character. For these, the decision of whether or not to bully depended on the 'kind of person they are' (m).

As previously discussed, many participants thought that their peers were more likely to bully online because of the absence of constraining principles. For many, this placed responsibility on individuals themselves to regulate their online activities. As one student put it: everyone must 'police themselves' (f). Some looked for external guidance to help them do this, such as the student who observed that they had 'their mum's voice in their head whenever they are online' (f).

Virtues considered by interviewees to be important when using the Internet included 'being kind and compassionate' ( $\mathrm{m}$ and $\mathrm{f}$ ); whilst another observed that: you have to take responsibility for yourself and be honest' (m). Self-discipline was also considered important insofar as the Internet is 'always on', permitting communication with others at any time of the day and from any location. Feelings and emotions were also given as reasons why young users do good and bad things online. For example, empathy was also raised as an important emotion as there is a need to think about the consequences of actions before sending online messages. A female participant stated:

You have to understand how what you're going to say is going to affect them and their perspectives so you have to imagine how they are going to be feeling, if you have said something to them. So you would have to be like cautious of like the consequences of your actions and be responsible for what you're going to say? (f)

The importance of making wise judgments when online was discussed by some of the participants. In order to make wise judgements they explained they had to draw on past experiences to work out the best course of action. For example, one female student commented: 'my friends all act the same online as they understand what it is like to be backstabbed' (f); and another, that 'sometimes you know afterwards you have done wrong - you read back and think why did I write that' (f). It was this process of learning through experience, and building up a bank of knowledge to guide action that the participants felt helped them make wise decisions when communicating online.

Although, as previously expressed, many participants felt that features of the Internet made it more likely that people would be bullied, there was also an understanding that some features might actually inhibit such actions. These features were: its connective properties; access to large audience; and the fact that written communication have a permanency that oral communications do not. Students felt that the larger audiences and connectivity made them more careful about what they wrote online, insofar as they were concerned about where their messages might go and who might see them. Likewise, some students observed that online communications are hard to erase and often have a life of their own. They explained that it is more difficult to prove if something was said verbally in the playground than online where the evidence can be seen in black and white.

A moral theory that prioritises human character over consequences and/or duties is helpful when seeking courses of action for dealing with cyber-bullying. This is because emphasis regarding educating good digital citizens can be firmly placed on the development of character as a guide to conduct online. This will be discussed in more detail below.

\section{Discussion}

The research reported on in this article has sought to break some new ground in the field. The merits of virtue ethics, by contrast with utilitarianism and deontology, have been 
examined through an analysis of the interview data. Deontology has been found to be a somewhat imperfect basis for online morality, with many of the participants admitting that they have a reduced sense of duty when they are in cyberspace. This is not meant as a general condemnation of deontology; only as an indication of the fact that cyberspace might carve up an area of 'moral space' that is not easily amenable to a rule-and-code based approach. Likewise, although utilitarianism offered some sound principles for moral behaviour on the Internet, it is not so easy to apply it in practice. The research findings show that calculating the consequences of any particular online interaction is difficult at best, and often impossible. Moreover, utilitarianism assumes empathy with the plight of other people, but the emotional identification underlying empathy seems to require (psychologically if not necessarily logically) the existence of particular rather than nonspecific others. That said, utilitarianism and deontology might continue to provide useful frameworks for future research into morality and the Internet, in various partial and specifically targeted ways. However, the findings from this research show that virtue ethics has some advantages over the other two theories.

One distinct advantage of virtue ethics is that it places the onus on young people to make wise decisions on the Internet when it might not be obvious what the right thing is to do. As the Internet is described as 'free' and often involves new experiences, young users are often faced with situations where there is no categorical imperative, or right course of action based on rational principles. In these situations users are required to make judgements about the right course of action, based on previous experience as well as their effective emotions and feelings. Virtue ethics allows for young users of the Internet to become wiser over time through the development of online practical wisdom, or what we could call 'cyber-phronesis'. While a deontological approach might continue to be seen as helpful to bolster general rules and guidance governing what is good and bad online conduct, and a utilitarian one to draw greater attention to harmful online consequences, a virtue ethical perspective would prioritise the formation of wise and virtuous online citizens. Such an approach might provide young people with resources to negotiate the inevitable moral dangers and challenges of using the Internet.

Adopting a virtue ethical theoretical base for research into the impact of the Internet on young people requires us to ask different questions. Perhaps most importantly is to ask how the character virtues of young people influence their use the Internet, rather than simply to assume that because the technology exists, immoral behaviour will inevitably ensue. Unnecessarily deterministic accounts should be avoided. The interviews show that young people perceive their relationship with the Internet to be reciprocal, rather than unidirectional. They recognised that it was how agents used the Internet that largely determined the consequences of their online actions: that there was nothing about the technology as such that made people cruel, or dishonest. From a virtue ethical perspective, technological determinism is implausible insofar as it is the character virtues of the users of the technology, rather than the technology itself, that determines online behaviour. From this viewpoint, the technology is neither good nor bad (although it has features that might encourage good or bad behaviour): it is the user that determines whether it is put to good or bad use.

\section{Conclusion}

It would not be desirable to draw any simple picture of user experience from the data presented in this article. Given the limited nature of the present research, any attempt to make universal claims is not possible. However, the findings discussed above may provide a useful basis upon which to construct a moral theoretical framework for future research into cyber-bullying in particular as well as perhaps other moral issues found online. The new opportunities that the Internet has opened up for young people require them more than ever to 'do the right thing'; not so much motivated by rules, duties or consequences (since these may not always be explicit), but by having the character to choose wisely between alternatives. An important question to ask in future research is how best to educate digitally virtuous citizens to help them make good and wise decisions. On the basis of the present study, virtue ethics arguably offers not only a promising theoretical basis for researching the influence of the Internet on character virtues, but also provides a promising practical strategy for dealing with online moral concerns. The educational implications of this research will be returned to in a later paper.

Open Access This article is distributed under the terms of the Creative Commons Attribution 4.0 International License (http://crea tivecommons.org/licenses/by/4.0/), which permits unrestricted use, distribution, and reproduction in any medium, provided you give appropriate credit to the original author(s) and the source, provide a link to the Creative Commons license, and indicate if changes were made.

\section{References}

Ackers, M. (2012). Cyberbullying: Through the eyes of children and young people. Educational Psychology in Practice, 28(2), 141-157.

Ali, A. (2013). Cyber-bullying taxonomies: Definition, forms, consequences and mitigation strategies. In 2013 5th International conference on computer science and information technology (CSIT) (p. 126-133). 
Ang, R. P., \& Goh, D. H. (2010). Cyberbullying among adolescents: The role of affective and cognitive empathy, and gender. Child Psychiatry and Human Development, 41(4), 387-397.

Anirban, S., \& Anoshua, C. (2011). Are social networking sites a source of online harassment for teens? Evidence from survey data. Children and Youth Services Review, 33(2), 284-290.

Anscombe, G. E. M. (1958). Modern moral philosophy. Philosophy, $33(124), 1-19$.

Arsenio, W., Adams, E., \& Gold, J. (2009). Social information processing, moral reasoning and emotion attributions. Relations with adolescents reactive and proactive aggression. Child Development, 80, 1739-1755.

Arthur, J., Kristjansson, K., Thomas, H., Kotzee, B., Ignatowitcz, A., \& Qiu, I. (2015). Virtuous medical practice. Birmingham: University of Birmingham. Accessed July 20, 2015 from http:// www.jubileecentre.ac.uk/userfiles/jubileecentre/pdf/Research\%20 Reports/Virtuous_Medical_Practice.pdf.

Bandura, A. (2002). Selective moral disengagement in the exercise of moral agency. Journal of Moral Education, 31(2), 101-119.

Belsey, B. (2005). Internet usage: Facts and news. Accessed September 17, 2012 from www.cyberbullying.ca.

BERA. (2011). Ethical guidelines for educational research. London: BERA.

Boyatzis, R. (1998). Transforming qualitative information: Thematic analysis and code development. Thousand Oaks, CA: Sage Publications.

Brydolf, C. (2007). Minding myspace: Balancing the benefits and risks of students' online social networks. Education Digest, 73(2), 4-8.

Campbell, M. (2005). Cyber-bullying: An old problem in a new guise? Australian Journal of Guidance and Counseling, 15(1), 68-76.

Couldry, N. (2010). Media ethics: Towards a framework for media producers and media consumers. In S. J. Eards \& H. Wasserman (Eds.), Media ethics beyond boarders: A global perspective. New York: Routledge.

Cross, D., Li, Q., Smith, P. K., \& Monks, H. (2012). Understanding and preventing cyberbullying. Where have we been and where should we be going? In Q. Li, D. Cross, \& P. K. Smith (Eds.), Cyberbullying in the global playground. Research from international perspectives (pp. 287-305). West Sussex: Wiley.

Cross, E., Richardson, B., Thaddaeus, D., \& Jessica, V. (2009). Protecting young people from cyberbullying. London: Beatbullying.

Elder, A. (2014). Excellent online friendships: An Aristotelian defense of social media. Ethics and Information Technology, 14(16), 287-297.

Froese-Germain, B. (2008). Bullying gets digital shot-in-the-arm. Education Canada, 48(4), 44-47.

Gini, G. (2006). Social cognition and moral cognition in bullying: What's wrong? Aggressive Behaviour, 32, 528-539.

Granitz, N., \& Loewy, D. (2007). Applying ethical theories: Interpreting and responding to student plagiarism. Journal of Business Ethics, 72(3), 293-306.

Harrison, T. (2014). The influence of the Internet on the character virtues of 11-14 year olds. Birmingham: University of Birmingham.

Hasebrink, U., Livingstone, S., Haddon, L., \& Olafsson, K. (2009). Comparing children's online opportunities and risks across Europe: Cross-national comparisons for EU Kids Online (2nd ed.). Deliverable D3.2, LSE, London, EU Kids Online. Accessed June 17, 2014 from http://eprints.lse.ac.uk/24368/1/D3.2_ Report-Cross_national_comparisons-2nd-edition.pdf.

Heary, C., \& Hennessy, E. (2002). The use of focus group interviews in paediatric health care research. Journal of Pediatric Psychology, 27(1), 47-57.
Heath, S., Brooks, R., Cleaver, E., \& Ireland, E. (2009). Researching Young people's lives. London: Sage.

Hoffman, M. L. (2000). Empathy and moral development: Implications for caring and justice. Cambridge: Cambridge University Press.

Horner, S. D. (2000). Focus on research methods: Using focus group methods with middle school children. Research in Nursing \& Health, 23(6), 510-517.

Krueger, R. (1994). Focus groups: A practical guide for applied research (2nd ed.). London: Sage Publications.

Layard, R., \& Dunn, J. (2009). A good childhood, searching for values in a competitive age. London: Penguin.

Lenhart, A. (2007). Cyberbullying. Washington, DC: Pew Research Center. Accessed November 20, 2013 from www.pewinternet. org/Reports/2007/Cyberbullying.aspx.

Lievens, E. (2011). Risk-reducing regulatory strategies for protecting minors in social networks. Strategy for Telecommunications, Information and Media, 13(6), 43-54.

Livingston, S. (2009). Children and the Internet. Cambridge: Polity Press.

Lyu, H. (2012). Internet policy in Korea: A preliminary framework for assigning moral and legal responsibility to agents in Internet activities. Government Information Quarterly, 29(3), 394-402.

MacIntyre, A. (1981). After virtue. Notre Dame: University of Notre Dame Press.

Malti, T., Gasser, L., \& Gutzwiller-Helfenfinger, E. (2010). Children's interpretive understanding, moral judgments, and emotion attributions: Relations to social behaviour. British Journal of Developmental Psychology, 28, 275-292.

McFall, M. T. (2012). Real character-friends: Aristotelian friendship, living together, and technology. Ethics and Information Technology, 14(3), 221-230.

Menesini, E., \& Camodeca, M. (2008). Shame and guilt as behaviour regulators: Relationships with bullying, victimization and prosocial behaviour. British Journal of Developmental Psychology, 26(2), 183-196.

Menesini, E., Nocentini, A., \& Calussi, P. (2011). The measurement of cyberbullying: Dimensional structure and relative item severity and discrimination. Cyberpsychology, Behaviour and Social Networking, 14(5), 267-274.

Menesini, E., Nocentini, A., \& Camodeca, M. (2013). Morality, values, traditional bullying, and cyberbullying in adolescence. The British Journal of Developmental Psychology, 31(1), 1-14.

Mishnan, F., Cook, C., Gadalla, T., Daciuk, J., \& Solomon, S. (2010). Cyber-bullying behaviours among middle and high school students. The American Journal of Orthopsychiatry, 80(3), 362-374.

Mishnan, F., Michael, S., \& Solomon, S. (2009). Ongoing and online: Children and youth's perceptions of cyberbullying. Children and Youth Services Review, 3(12), 1222-1228.

Ofcom. (2014). Children and parents: Media use and attitudes report. Accessed July 10, 2015 from http://stakeholders.ofcom.org.uk/ binaries/research/media-literacy/media-use-attitudes-14/Childrens_ 2014_Report.pdf.

Perren, S., \& Gutzwiller-Helfenfinger, E. (2012). Cyberbullying and traditional bullying in adolescence: Differential roles of moral disengagement, moral emotions, and moral values. European Journal of Developmental Psychology, 9, 195-209.

Plaisance, P. (2013). Virtue ethics and digital flourishing: An application of Philippa foot to life online. Journal of Mass Media Ethics, 28(3), 91-102.

Pozzoli, T., \& Gini, G. (2010). Active defending and passive bystanding behavior in bullying: The role of personal characteristics and perceived peer pressure. Journal of Abnormal Child Psychology, 38, 815-827. 
Robson, C. (2011). Real world research. Oxford: Blackwell Publishers.

Shariff, S. (2008). Cyber-bullying: Issues and solutions for the school the classroom and the home. Oxon: Routledge.

Shariff, S., \& Hoff, D. L. (2007). Cyberbullying: Clarifying legal boundaries for school supervision in cyberspace. International Journal of Cyber Criminology. http://www.cybercrimjournal.co. nr. Accessed 12 Oct 2013.

Suler, J. (2004). The online disinhibition effect. Cyberpsychology and Behaviour, 7(3), 321-326.

Tokunaga, R. S. (2010). Following you home from school: A critical review and synthesis of research on cyberbullying victimisation. Computers in Human Behaviour, 26(3), 277-287.

Valkenburg, P. M., Peter, J. S., \& Schouten, A. P. (2006). Friend networking sites and their relationship to adolescents' well-being and social self-esteem. Cyberpsychology Behavior, 9, 584-590.
Vallor, S. (2010). Social networking technology and the virtues. Ethics and Information Technology, 12(2), 157-170.

Weisband, S., \& Kiesler, S. (1996). Self-disclosure on computer forms: Meta-analysis and implications. In Proceedings of the SIGCHI conference on human factors in computing systems (pp. $3-10)$.

Willard, N. (2002). Computer ethics, etiquette, and safety for the 21stcentury student. Eugene, OR: ISTE.

Williams, B. (1985). Ethics and the limitations of philosophy. Cambridge: Harvard University Press.

Winter, R. E., \& Leneway, R. J. (2008). Cyberbullying-Terror in the classroom: What can be done? Accessed January 15, 2013 from http://www.chaminade.org/cyberbullying.htm.

Zhang, X. (2010). Charging children with child pornography-Using the legal system to handle the problem of sexting. Computer Law \& Security Review, 26(3), 251-259. 